\title{
Validation and calibration of Source water quality models in the Great Barrier Reef catchments
}

\author{
McCloskey, G.L. ${ }^{\text {a }}$ and Waters, D.K. \\ ${ }^{a}$ Queensland Department of Natural Resources and Mines \\ Email: gillian.mccloskey@dnrm.gld.gov.au
}

\begin{abstract}
The Paddock to Reef (P2R) Integrated Monitoring, Modelling and Reporting Program uses modelled catchment loads to estimate annual load reductions as a result of improved management practices in the Great Barrier Reef (GBR) catchments. Calibrating and validating catchment models across a large spatial scale is challenging, and requires a range of approaches to continue to refine and improve modelled load estimates. Catchment models have been built for the six Natural Resource Management (NRM) regions draining to the GBR in the Source framework. The NRM regions range in area from $9,000 \mathrm{~km}^{2}$ to 155,000 $\mathrm{km}^{2}$, with the total modelled area $423,000 \mathrm{~km}^{2}$. Load estimates are modelled for 10 water quality constituents.
\end{abstract}

Many improvements have been made over the past seven years to improve confidence in modelled loads. An example includes hydrology recalibration and baseflow optimisation to align with estimates derived from gauged flow. Typically, the larger, drier regions required more gauges to be recalibrated than for the wetter regions. In Cape York (CY) following recalibration of the model, the baseflow proportion was improved from an average of $43 \%$ to $33 \%$, which better aligns with the baseflow estimate from gauged flow of $31 \%$.

A second notable model update is the improved representation of Dissolved Inorganic Nitrogen (DIN) in sugarcane areas. The DIN runoff model was updated to incorporate a new algorithm which correlates fertiliser input to nitrogen in runoff, derived from the pool of P2R field monitoring data. This daily model of DIN concentration in runoff was based on $>200$ sugarcane field monitored DIN runoff events. These changes have resulted in modelled DIN loads now being within $\pm 30 \%$ of measured loads in the Wet Tropics (WT), compared to $\pm 50 \%$ in previous model iterations.

The improved representation of fine sediment sources as a result of new datasets (for example, gully mapping in CY, Burdekin and Fitzroy) is another example of model calibration using the most up-to-date data. CY is typically a data poor region and early model estimates of the hillslope/gully/streambank contribution to fine sediment loads suggested that up to $90 \%$ of the fine sediment load was derived from hillslope sources. Recent field surveys combined with LIDAR data and a desktop gully mapping exercise in the Normanby basin conclude that gullies are the major source of sediment in CY. The updated gully map was incorporated into the Source model, and gullies now account for $>70 \%$ of the fine sediment load in the Normanby basin.

A major component of the P2R program is the catchment loads monitoring program critical for model validation. The number of monitoring sites has expanded from 26 in 2006 to 43 in 2017. This means that 85\% of the sediment and nutrient loads exported are now monitored across the GBR. As the pool of water quality data increases both spatially and temporally, there has been a shift to manual model calibration to align with monitoring data as opposed to using the data for validation as was the case in the early years of the program.

Whilst the average annual load estimates for the models have not changed significantly there is much greater confidence in the relative contribution of constituents, for example sediment sources and sinks, or DIN loss path ways (surface versus subsurface drainage) from different land uses. This leads to greater confidence in the model outputs, particularly from external stakeholders.

At the outset of the P2R modelling program there was limited observed data available to calibrate and/or validate modelled loads. Over the course of the program, knowledge gaps were identified and prioritised, resulting in targeted research being undertaken. This has enabled the refinement of different aspects of the models in each region. When considering a long-term modelling exercise, that is data poor, the model improvement cycle should be flexible enough to for regular updates to algorithms in the models, input data sets, and modelled constituent loads. Model validation must draw on a range of data sources to constrain the models. The P2R modelling has been highly beneficial for identification of dominant sources of constituents, guided water quality monitoring and research, and just as importantly, generated debate about load predictions across the GBR.

Keywords: GBR modelling, water quality, model validation and calibration, DIN, fine sediment 
McCloskey, G.L. and Waters, D.K., Validation and calibration of Source Catchments water quality models in the Great Barrier Reef Catchments

\section{INTRODUCTION}

Catchment modelling is used as one of multiple lines of evidence to report on progress towards the 2013 Reef Water Quality Protection Plan (Reef Plan (Department of the Premier and Cabinet 2013)) water quality targets. Reef Plan is a collaborative policy that includes a set of water quality and land management practice targets for catchments discharging to the Great Barrier Reef (GBR). The Reef Plan water quality targets were set for the whole of the GBR, which encompasses six contributing NRM regions: Cape York (CY), Wet Tropics (WT), Burdekin (BU), Mackay Whitsunday (MW), Fitzroy (FZ) and the Burnett Mary (BM). The NRM regions range in area from $9,000 \mathrm{~km}^{2}$ to $155,000 \mathrm{~km}^{2}$, with the total modelled area $423,000 \mathrm{~km}^{2}$ (Figure 1).

The GBR Source modelling framework and the Dynamic SedNet plugin enable load estimates to be modelled for 10 water quality constituents. At the outset of the Paddock to Reef (P2R) modelling program there was limited water quality data available to validate and/or calibrate modelled loads. The P2R Program strives for continual improvement in all areas. Therefore, the catchment modelling team aims for continual improvement of the modelling approach to better predict pollutant loads and improvements in water quality as a result of improved management practice adoption. Over the course of the program, knowledge gaps have been identified (through monitoring and modelling feedback loops) and prioritised, resulting in targeted research being undertaken. This has enabled the refinement of different aspects of the models in each region.

Additional lines of evidence used in the P2R program to report on progress to water quality targets includes catchment and paddock scale monitoring. At the outset of the P2R program there was four years of catchment scale water quality data in most of the GBR NRM regions. In some regions, this was the only source of water quality data available to validate and calibrate the Source

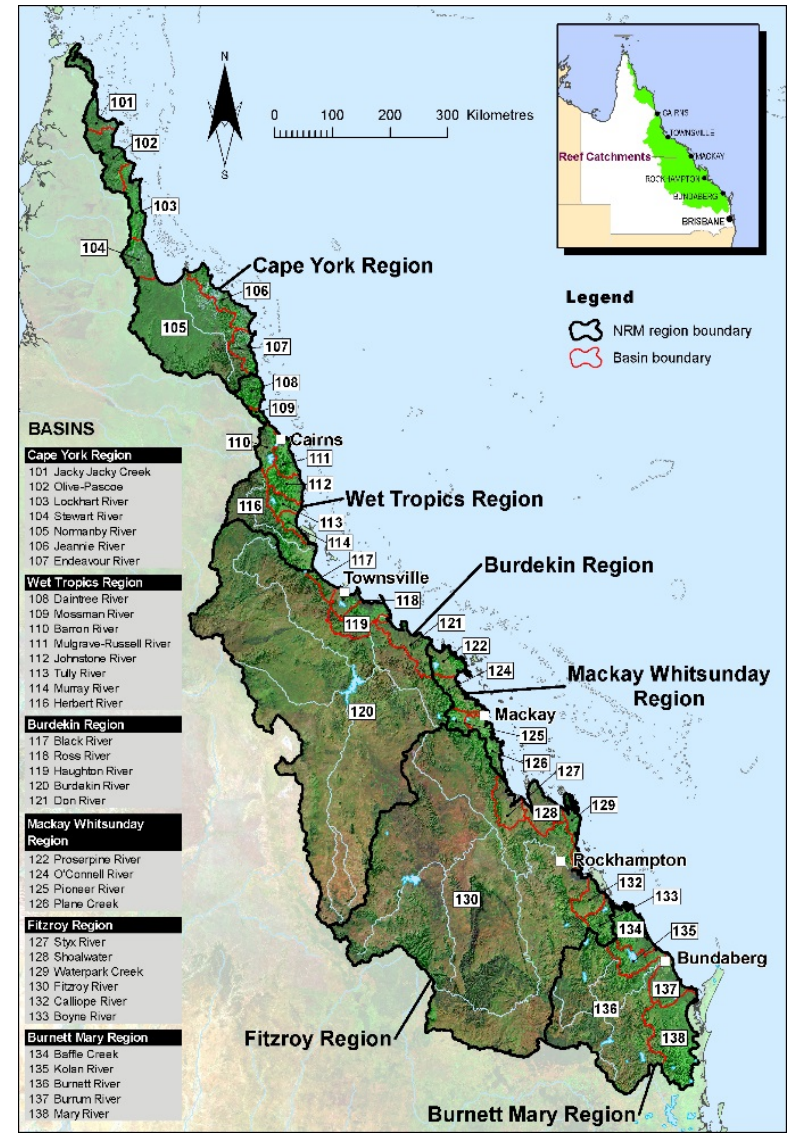

Figure 1. Great Barrier Reef NRM regions models. The continuation of the P2R program and its catchment and paddock scale water quality modelling and monitoring components has enabled the catchment models to be updated on a regular basis on the grounds of new monitored data. There is now a pool of monitored data available, from both the P2R catchment and paddock monitoring, and targeted research from other sources that mean the models can utilise a portion of monitored data for calibration purposes and some for validation.

Many improvements have been made over the past seven years to improve confidence in modelled loads as a result of additional water quality data for validation/calibration. Examples of model improvements include hydrology calibration updates, improved representation of the sources and sinks of fine sediment, and the improved representation of Dissolved Inorganic Nitrogen (DIN) in sugarcane land uses. This paper summarises the major model improvements to have occurred across all of the GBR Source models, as well as some regionally specific improvements due to an increased pool of water quality data. Outcomes of the model changes and validation of constituent loads are also presented.

\section{METHODS AND RESULTS}

To allow a continuous improvement approach to GBR water quality modelling, the model improvement cycle should be flexible to allow for periodic updates to the algorithms in the models, input data sets, and modelled constituent loads. Between GBR Report Card releases there have been several upgrades to the Source platform, developed and maintained by eWater Ltd as well as several upgrades to the GBR component models maintained by DNRM. 
McCloskey, G.L. and Waters, D.K., Validation and calibration of Source Catchments water quality models in the Great Barrier Reef Catchments

In 2014, the model run period was extended by five years and now runs from 1986-2014. The extended run period allows the models to be validated against an additional five years of water quality monitoring data (McCloskey et al., 2017a, b). Importantly the extended period includes the extreme flood events of 2010-2011. The extreme wet years provide additional calibration points at the high flow end, important for improving load predictions.

\subsection{Hydrology calibration}

Unlike the water quality component of Source modelling, there was ample data available in most regions to undertake comprehensive hydrology calibrations. The SimHyd rainfall runoff model was chosen at the commencement of the program in 2009 due to its extensive application and proven performance to satisfactorily estimate streamflow across Australia (Chiew et al. 2002) including in the Fitzroy Basin (Ellis et al. 2009). However the calibration resulted in some large differences between observed and predicted runoff (up to $30 \%$ bias) and misalignment in simulated peak flow and recession curves for large flow events for numerous gauging stations. Zhang et al. (2013) found that the Sacramento rainfall-runoff model achieved lower bias of total flow volume compared to SimHyd. Importantly, the Sacramento model achieved better results in the simulation of the recessions of the flow hydrograph, peak flows and the timing of big events compared to SimHyd. Large events are the major contributors to sediment load generation and export for GBR catchments, thus improving the simulation of large events was the main objective of recalibration. For all GBR NRM regions there was a marked improvement in the flow bias/total volume percent difference (Table 1), but this was particularly pronounced in the $\mathrm{BU}$ and $\mathrm{FZ}$ regions, where under-predictions of flow were improved from $-71 \%$ and $-35 \%$ respectively, to $-6 \%$.

Table 1. Summary of hydrology calibration results between the SimHyd and Sacramento calibrations

\begin{tabular}{|l|c|c|}
\hline \multirow{2}{*}{ NRM Region } & \multicolumn{2}{|c|}{ Flow Bias range (\%) } \\
\cline { 2 - 3 } & SimHyd & Sacramento \\
\hline CY & $-18 \%-25 \%$ & $-5 \%-4 \%$ \\
\hline WT & $-31 \%-7 \%$ & $-8 \%-5 \%$ \\
\hline BU & $-60 \%-40 \%$ & $-7 \%-5 \%$ \\
\hline MW & $-27 \%-9 \%$ & $-23 \%-1 \%$ \\
\hline FZ & $-71 \%-22 \%$ & $-6 \%-13 \%$ \\
\hline BM & $-35 \%-52 \%$ & $-6 \%-4 \%$ \\
\hline
\end{tabular}

Further analysis of the Sacramento recalibration highlighted that baseflow proportions in many regions were too high compared to baseflow proportions estimated from gauging station data (i.e. observed baseflow). The 'observed' baseflow was estimated using the Lyne and Hollick (1979) filter method which applies a smoothing filter to daily flow which provides a means of splitting daily flow into baseflow and quickflow. To rectify the discrepancy between the two, the objective function used in the calibration was modified to include a term which enables the minimization of the difference between the simulated baseflow and the observed baseflow proportion. The result of this recalibration was a better representation of baseflow against our baseflow filter measure, and an increase in GBR average annual flow of $1 \%$, with the $\mathrm{BM}$ region increasing by $13 \%$ and $\mathrm{CY}$ decreasing by $3 \%$.

\subsection{Improved representation of sediment sources and sinks}

Previous modelling across the GBR catchments suggested that hillslope erosion was the dominant source of fine sediment (Brodie et al. 2003). More recent literature indicates that sub-surface erosion is the dominant source across many of the GBR catchments including the Normanby (Olley et al. 2013), Fitzroy (Hughes et al. 2009), and Burdekin basins (Bartley et al. 2007, Wilkinson et al. 2013), and that the proportion of hillslope/streambank/gully erosion across the GBR is similar. These data sources, and other related studies such as improved gully mapping (Brooks et al. 2013), have enabled the Source models to be updated with new data sets where appropriate and calibrated such that in those locations. Relative sediment contributions from the different sources reflected published findings. Using all the available information to calibrate, and then validate, the Source models has resulted in a better representation of fine sediment sources and sinks. Some examples are provided that describe model data input and calibration updates related to sources and sinks of fine sediment.

Hillslope erosion is calculated in the GBR Source models via the Revised Universal Soil Loss equation (RUSLE), which requires a ground cover value input. Briefly, the models for Report Card 2013 (RC2013) and prior, used the Bare Ground Index (BGI) (Scarth et al. 2006) as the cover input for the RUSLE c-factor parameter, and a spatial layer was created for each year towards the end the dry season. Several shortcomings 
McCloskey, G.L. and Waters, D.K., Validation and calibration of Source Catchments water quality models in the Great Barrier Reef Catchments

were identified with the input datasets (Waters et al. 2014). Three significant changes to the ground cover inputs were made. Firstly, estimates of ground cover levels under trees has been made available by the remote sensing team, previously unavailable. Secondly, the temporal resolution of ground cover data has increased from one to four scenes per year. Finally, an improvement was made to how the cover factor in the soil erosion models (C-factor) was derived from the remotely sensed data. Combined, these changes reduced the average cover estimates in all NRM regions by approximately $20 \%$. This resulted in a higher hillslope load being generated which better aligned to plot studies.

In most regions, instream deposition and remobilisation were not enabled until the 2015 model iterations due to a lack of data to validate this component of the models. These processes are in a state of continuous flux between deposition and remobilisation (Wilkinson et al. 2010). Recently published research highlights these processes are an important part of the sediment budget story (Brooks et al. 2013), and thus they've been enabled in models post 2015. To validate this component of the models it was assumed that the net balance of instream deposition and remobilisation would be approximately the same (Figure 1). In the CY region, there is recently published field data on the sources and sinks of fine sediment for the Normanby Basin. This data suggests that approximately $55 \%$ of the generated load is lost to floodplain and instream deposition. The Source model was manually calibrated to ensure the relative contributions from different sediment sources of the budget reflected this with $63 \%$ of the generated load being stored. Furthermore, according to field data, $75 \%$ is stored on the floodplain and 25\% instream for the Normanby Basin (Brooks et al. 2013). The model has $92 \%$ of fine sediment stored on the floodplain and $8 \%$ instream. It was possible to use the measured data to calibrate the model, adjusting factors such as the proportion available for instream deposition and the initial store of fine sediment, to ensure the modelled outputs were of a similar order. While this is a good result in terms of comparison between measured and modelled data, this may be an avenue for further refinement in the CY model.

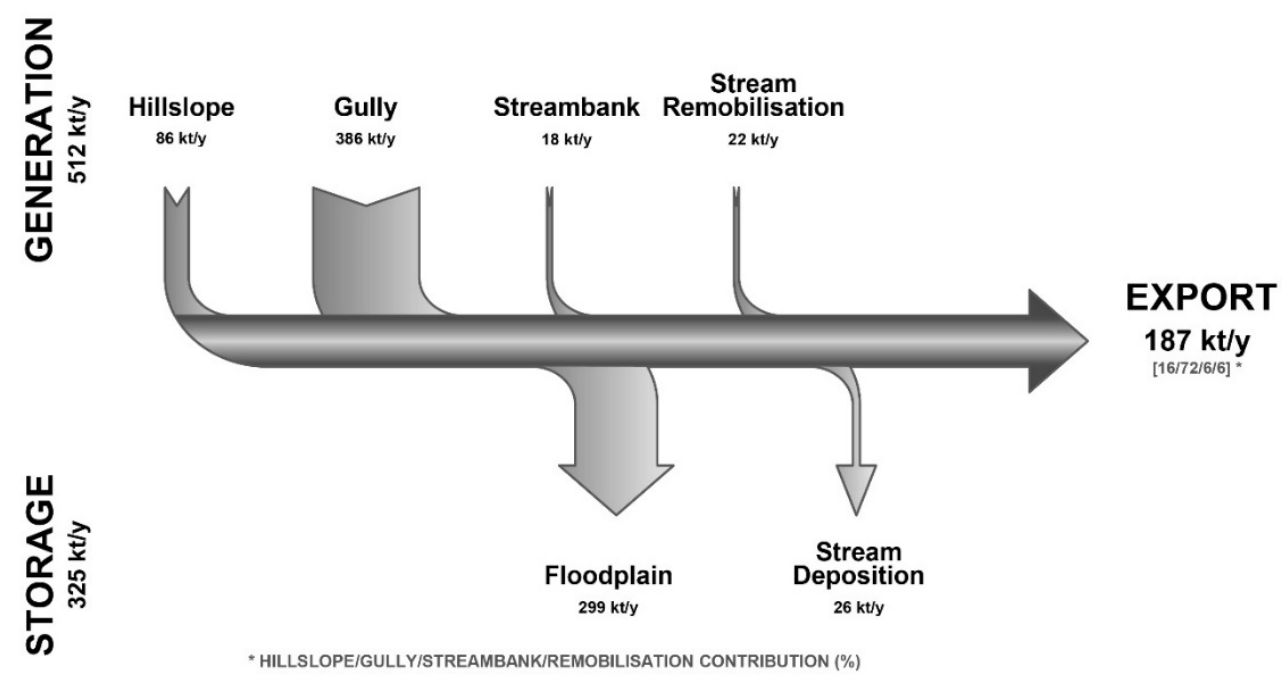

Figure 2. Fine sediment source sink budget diagram for the Normanby Basin

In $\mathrm{CY}, \mathrm{BU}$ and $\mathrm{FZ}$ an updated gully density layer was used to calculate gully sediment and particulate nutrient loads for the 2014 model runs and beyond. Previously, the NLWRA gully density maps (Hughes et al. 2001) were used as the best available data sets. This data was shown to provide a poor representation of gullies in Queensland coastal areas (Hughes et al. 2001). Since 2013, DNRM have been mapping gully locations across priority areas of the GBR to improve on the NLWRA estimates of gully density (Darr 2017), and this work has been incorporated into the models. In the Fitzroy basin the generated gully fine sediment load doubled for RC2014 as a result of the improved gully density map, despite being coupled with a reduction in the gully cross sectional area. In conjunction with the DNRM mapping, CY gully change data from a two year study undertaken by Brooks et al. (2013) in the Normanby Basin was used to derive a gully density layer for the Normanby Basin and incorporated into the CY model after 2014. This had a significant effect on the distribution of sources and sinks in the Normanby Basin in the CY model with the updated input data significantly increasing the load from gullies (Figure 2). 
McCloskey, G.L. and Waters, D.K., Validation and calibration of Source Catchments water quality models in the Great Barrier Reef Catchments

\subsection{DIN in sugarcane}

As part of the P2R paddock scale monitoring a number of field trials continue to be conducted on sugarcane sites in the WT and MW (Rohde et al. 2013, Masters et al. 2017). Improvements were made to the sugarcane paddock model which subsequently impacted on DIN loads generated within the catchment model (note: outputs from the paddock models are aggregated for a landuse within a subcatchment and uploaded into the catchment models). Firstly, a modification was made to the DIN generation algorithm which improved the correlation between fertiliser inputs and DIN runoff concentration (Fraser et al. 2017). This was derived from the GBR wide pool of experimental data (collected as part of the paddock scale monitoring (Masters et al. 2017)) to improve the prediction of DIN in runoff across a season. Secondly, functionality was added to enable a proportion of the DIN reported as deep drainage from the sugarcane paddock modelling to be returned to streamflow.

The two refinements to the sugarcane DIN modelling are important additions to the modelling framework. The modification to surface DIN generation has resulted in smaller DIN load in surface runoff than previously modelled. However, the surface runoff loads better reflect experimental data. The inclusion of subsurface DIN not only improved load estimates at the gauges, but better reflected the transport processes occurring in a number of irrigated cane areas, namely the return of runoff and associated loads of constituents to streams via subsurface pathways (Armour et al. 2013, Rasiah et al. 2013). Importantly the new approach now enables improved management of DIN via reduced fertiliser inputs to be expressed in stream water quality.

In the WT model runs the majority of the sugarcane DIN export load was from seepage (a proportion of the DIN escaping the root zone as deep drainage) (89\%) and the remainder (11\%) from surface runoff. The majority of the deep drainage component was returned to the stream as seepage (91\%). A study of runoff and deep drainage in sugarcane farming in the Murray Basin (WT) showed that the major loss pathway was from deep drainage from a permeable soil type (Armour et al. 2013). Deep drainage from this study accounted for between $23-42 \%$ of annual rainfall (from two sites). Armour et al. (2013) found that the inorganic N loss (mainly nitrate) was up to $13 \mathrm{~kg} \mathrm{~N} / \mathrm{ha} / \mathrm{yr}$. The modelled average areal rate of DIN export from sugarcane across the WT was $12 \mathrm{~kg} / \mathrm{ha} / \mathrm{yr}$. The modelled areal rate for DIN sugarcane export from the Murray Basin was also $12 \mathrm{~kg} / \mathrm{ha} / \mathrm{yr}$ (modelled basin range $7-17 \mathrm{~kg} / \mathrm{ha} / \mathrm{yr}$ ). Updates to the DIN model have resulted in improved results (percent difference) compared to the measured data. In three of the WT catchments containing significant areas of sugarcane, the difference between measured and modelled DIN data improved from: $+50 \%$ to $-29 \%$ in the Herbert Basin; $-20 \%$ to $-16 \%$ in the Tully Basin; and, $-25 \%$ to $-9 \%$ in the North Johnstone Basin.

\section{DISCUSSION AND CONCLUSIONS}

In this paper model calibration and validation in data poor regions is discussed and the value of adopting a flexible modelling framework outlined. The modelling approach should be flexible enough to allow minor updates (for example, between annual model runs) and major updates (e.g. five yearly in the GBR program) to enable the continuous improvement of models (data inputs, algorithms, platform upgrades) and modelled load estimation.

The P2R program uses multiple lines of evidence to inform progress towards Reef Plan water quality targets, namely paddock and catchment scale monitoring and modelling. In doing so, these multiple lines of evidence and or programs work collaboratively to prioritise knowledge gaps and research. For example, modelling has been used to prioritise where water quality sites could be moved and where new monitoring sites need to be located. Where major discrepancies between monitoring and modelled loads is identified further investigation is undertaken, hence monitoring is informing modelling and vice versa. It has been recognised that the level of collaboration between components of the P2R program is rare, and that the multiple lines of evidence approach improves confidence in the modelled results (Jakeman et al. 2015).

A challenge presented by this continuous improvement to catchment models is the communication of changes to the wider audience. To date, the catchment modelling program has released a series of technical reports (Waters et al. 2014, McCloskey et al. 2017a, b). These reports outline the changes between Report Cards (i.e. model runs) including changes to modelled load estimates. Communicating the how and why of model changes remains one of our greatest challenges, particularly to those without a modelling background.

Having the ability to update models with an ever increasing pool of observed data, is challenging although it has improved the modelled loads. The GBR Source modelling program has been recognised as one of the "most sophisticated and well-designed modelling exercises to evaluate the progress of a major program to improve natural resource management' (Jakeman et al. 2015). 
McCloskey, G.L. and Waters, D.K., Validation and calibration of Source Catchments water quality models in the Great Barrier Reef Catchments

\section{REFERENCES}

Armour, J. D., P. N. Nelson, J. W. Daniells, V. Rasiah and N. G. Inman-Bamber (2013). "Nitrogen leaching from the root zone of sugarcane and bananas in the humid tropics of Australia." Agriculture, Ecosystems and Environment 180: 68-78.

Bartley, R., A. Hawdon, D. A. Post and C. H. Roth (2007). "A sediment budget for a grazed semi-arid catchment in the Burdekin basin, Australia." Geomorphology 87(4): 302-321.

Brodie, J., L. A. McKergow, I. P. Prosser, M. Furnas, A. O. Hughes and H. Hunter (2003). Sources of sediment and nutrient exports to the Great Barrier Reef World Heritage Area. James Cook University, Townsville, Australian Centre for Tropical Freshwater Research. 03/11.

Brooks, A., J. Spencer, J. Olley, T. Pietsch, D. Borombovits, G. Curwen, J. Shellberg, C. Howley, A. Gleeson, A. Simon, N. Bankhead, D. Klimetz, L. Eslami-Endargoli and A. Bourgeault (2013). An emprically-based sediment budget for the Normanby Basin: sediment sources, sinks, and drivers on the Cape York Savannah, Australian Rivers Institute, Griffith University: 506pp.

Chiew, F. H. S., M. C. Peel and A. W. Western (2002). 'Application and testing of the simple rainfall-runoff model SIMHYD'. Mathematical models of small watershed hydrology and applications. V. P. Singh and D. K. Frevert. Littleton, Colorado, Water Resources Publication: 335-367.

Darr, S. (2017). Improving gully density maps for modelling water quality within the Great Barrier Reef. MODSIM 2017. Hobart, Tasmania.

Department of the Premier and Cabinet (2013). Reef Water Quality Protection Plan, 2013, Securing the health and resilience of the Great Barrier Reef World Heritage Area and adjacent catchments, Reef Water Quality Protection Plan Secretariat. www.reefplan.qld.gov.au.

Ellis, R., J. Doherty, R. Searle and K. B. Moodie (2009). Applying PEST (Parameter ESTimation) to improve parameter estimation and uncertainty analysis in WaterCAST models. 18th World IMACS Congress and MODSIM09 International Congress on Modelling and Simulation: Interfacing Modelling and Simulation with Mathematical and Computational Sciences, Cairns, Modelling and Simulation Society of Australia and New Zealand and International Association for Mathematics.

Fraser, G., K. Rohde and M. Silburn (2017). "Fertiliser management effects on dissolved inorganic nitrogen in runoff from Australian sugarcane farms." Environmental Monitoring and Assessment 189(8).

Hughes, A. O., J. M. Olley, J. C. Croke and L. A. McKergow (2009). "Sediment source changes over the last 250 years in a dry-tropical catchment, central Queensland, Australia." Geomorphology 104(3-4): 262-275.

Hughes, A. O., I. P. Prosser, J. Stevenson, A. Scott, H. Lu, J. Gallant and C. J. Moran (2001). Gully erosion mapping for the National Land and Water Resourced Audit. Canberra, Australia, CSIRO Land and Water.

Jakeman, A. J., I. Prosser, R. Grayson and M. Littleboy (2015). An Independent Review of the Paddock Modelling and Catchment Modelling Program. Brsibane, Department of Natural Resources and Mines: 13.

Lyne, V. and M. Hollick (1979). Stochastic time variable rainfall-runoff modelling, Perth, Institution of Engineers National Conference Publication.

Masters, B., N. Tahir, J. Fries, C. Mortimore, N. Enderlin and J. Armour (2017). Paddock scale water quality monitoring of nitrogen fertiliser management practices in sugarcane cropping : 2014-2016 technical report Wet Tropics region. Mareeba, Qld., Department of Natural Resources and Mines: 1 online resource (x, 57 pages : colour illustrations.).

McCloskey, G. L., D. Waters, R. Baheerathan, S. Darr, C. Dougall, R. Ellis, B. Fentie and L. R. Hateley (2017a). Modelling reductions of pollutant loads due to improved management practices in the Great Barrier Reef catchments: updated methodology and results. Technical Report for Reef Report Card 2014, Queensland Department of Natural Resources and Mines.

McCloskey, G. L., D. Waters, R. Baheerathan, S. Darr, C. Dougall, R. Ellis, B. Fentie and L. R. Hateley (2017b). Modelling reductions of pollutant loads due to improved management practices in the Great Barrier Reef catchments: updated methodology and results. Technical Report for Reef Report Card 2015, Queensland Department of Natural Resources and Mines. 
McCloskey, G.L. and Waters, D.K., Validation and calibration of Source Catchments water quality models in the Great Barrier Reef Catchments

Olley, J., A. Brooks, J. Spencer, T. Pietsch and D. Borombovits (2013). "Subsoil erosion dominates the supply of fine sediment to rivers draining into Princess Charlotte Bay, Australia." Journal of environmental radioactivity 124: 121-129.

Rasiah, V., J. D. Armour and P. N. Nelson (2013). "Nitrate in shallow fluctuating groundwater under sugarcane: Quantifying the lateral export quantities to surface waters." Agriculture, Ecosystems and Environment 180: 103-110.

Rohde, K., J. Agnew and K. McDuffie (2013). Paddock to sub-catchment scale water monitoring of sugarcane management practices : final report 2009/10 to 2011/12 wet seasons Mackay Whitsunday region. Mackay, Department of Natural Resources and Mines: 1 online resource (x, 67 pages).

Scarth, P., M. Byrne, T. Danaher, B. Henry, R. Hassett, J. Carter and P. Timmers (2006). State of the paddock: monitoring condition and trend in groundcover across Queensland. In: Proc. of the 13th Australasian Remote Sensing Conference, Earth observation: from science to solutions, Canberra, Spatial Sciences Institute (Australia).

Waters, D. K., C. Carroll, R. Ellis, L. R. Hateley, G. L. McCloskey, R. Packett, C. Dougall and B. Fentie (2014). Modelling reductions of pollutant loads due to improved management practices in the Great Barrier Reef Catchments: Whole of GBR, Technical Report, Volume 1. Brisbane, Queensland Department of Natural Resources and Mines.

Wilkinson, S., F. Cook, R. Bartley, A. Henderson, R. Searle, T. Ellis, P. Jordan and A. Miller (2010). Specification for Sediment, Nutrient and Pesticide Generation and Transport Modules in Source Catchments. Canberra, eWater Cooperative Research Centre.

Wilkinson, S. N., G. J. Hancock, R. Bartley, A. A. Hawdon and R. J. Keen (2013). "Using sediment tracing to assess processes and spatial patterns of erosion in grazed rangelands, Burdekin River basin, Australia." Agriculture, Ecosystems and Environment 180: 90-102.

Zhang, X., D. Waters and R. Ellis (2013). Evaluation of Simhyd, Sacramento and GR4J rainfall runoff models in two contrasting Great Barrier Reef catchments. MODSIM 2013, 20th International Conference on Modelling and Simulation, Adelaide, South Australia, Modelling and Simulation Society of Australia and New Zealand. 